\title{
A Twin Study of Dietary Restraint, Disinhibition and Hunger: An Examination of the Eating Inventory (Three Factor Eating Questionnaire)
}

\author{
Benjamin M. Neale', Suzanne E. Mazzeo², and Cynthia M. Bulik \\ ' Department of Psychiatry, Virginia Institute for Psychiatric and Behavioral Genetics, Virginia Commonwealth University \\ ${ }^{2}$ Department of Psychology, Virginia Commonwealth University
}

\begin{abstract}
The Eating Inventory (EI) is commonly used to measure a range of eating behaviors. It includes three subscales: Cognitive Restraint, Hunger, and Disinhibition. In this study, we decomposed the variance of the three subscales, and evaluated the genetic, common environment and specific environmental effects on each in a sample of female-female twin pairs. Multivariate models were also used to examine whether the El represented three individual factors, or whether there was extensive covariance among subscales. Heritabilities were estimated at $45 \%(\mathrm{Cl}$ of $32-57 \%)$ for Disinhibition, $8 \%$ (Cl of $0-38 \%)$ for Hunger, and $0 \%(\mathrm{Cl}$ of $0-30 \%)$ for Restraint. Common environmental influences were estimated at $0 \%(\mathrm{Cl}$ of $0-23 \%)$ for Disinhibition, $16 \%(\mathrm{Cl}$ of $0-34 \%)$ for Hunger, and $31 \%(4-42 \%)$ for Restraint. Specific environmental influences accounted for the rest of the variance of the subscales. However, multivariate modeling indicated that Disinhibition and Hunger covaried significantly, indicating that these two subscales are influenced by the same set of genetic factors. Furthermore, Restraint appeared to be empirically distinct from Hunger or Disinhibition.
\end{abstract}

\section{Role of Genetic and Environmental Factors in the Etiology of Obesity}

Obesity is increasingly prevalent in western societies. Indeed, although estimates vary across ethnic and ancestral subgroups, recent statistics suggest that approximately 20\% of the United States' population is obese (Mokdad, 1999, 2001). This trend has received significant attention in recent years, due to the well-documented link between obesity and many chronic illnesses (Manson et al., 2002; Must et al., 1999; Pi-Sunyer, 2002). The scope and significance of the obesity epidemic demand that this disease be considered a high research priority (Brownell \& Wadden, 1992). Thus, genetic and environmental influences on its etiology are the focus of significant attention.

\section{Genetic Influences on Obesity}

Although rare genetic variants have been identified that affect the development of some forms of obesity and related metabolic conditions, obesity is a classic complex trait influenced by both multiple genetic and multiple environmental influences (Bouchard, 2002; Bouchard et al., 1998).
Family and twin studies suggest that obesity is familial, and that this familiality is due primarily to genetic factors (e.g., Hewitt, 1997; Maes et al., 1997; Stunkard et al., 1990). Heritability estimates derived from twin studies of BMI have, however, varied widely, from $30 \%$ to $80 \%$ (see Bouchard et al., 1998; Hewitt, 1997; Maes et al., 1997 for reviews). Further, several studies have found that shared environment does not account for significant proportion of variance in BMI, even in studies of young children (e.g., Bodurtha et al., 1990; Cardon, 1995). Nonetheless, the rapidity with which the obesity epidemic has burgeoned suggests the presence of profound environmental influences. Consequently, there has also been significant attention paid to the contribution of environment to BMI.

\section{Environmental Influences on Obesity}

Environmental factors such as the increased availability and aggressive marketing of energy-dense processed foods, "super-sized" portions, and the impact of sedentary leisure activities including television and internet use, have contributed to the rising rate of obesity in Western society (Brownell, 2002; French et al., 2001). For example, between the late 1970s and mid-1990s, the number of meals and snacks eaten at fast-food restaurants increased $200 \%$, and soft drink consumption increased $131 \%$ (French et al., 2001). In addition, time spent in sedentary activities, such as television viewing, increased dramatically in recent years; the average American aged 12 or older watches approximately 28 hours of television per week (French et al., 2001)! Indeed, because of these pervasive environmental influences, many have labeled modern Western society "obesogenic" (e.g., Bouchard, 2002; Bulik \& Allison, 2001, 2002).

Address for correspondence: Cynthia M. Bulik, Department of Psychiatry, 1st Floor Neurosciences, Hospital Rm 40622, CB\#7160, University of North Carolina, Chapel Hill, NC 27599-7160. Email: cbulik@med.unc.edu.au 


\section{Gene-Environment Interaction}

Based on the variability in heritability estimates of BMI, and the pervasive environmental influences on body weight regulation, some have suggested that expression of genetic predispositions to obesity may depend on the presence of certain contextual triggers (e.g., Bouchard, 2002; Bouchard et al., 1998). De Castro (1997, 1999a, 1999b) explored the influence of genetics and environment on facets of eating behavior in a series of twin studies, and found that genetic influences affected overall meal size, daily food intake (de Castro, 1999a, 1999b), and self-reports of hunger (1999b). Results from de Castro's series of studies suggest that it is important to study how genetics and environment might act in concert to influence patterns of food intake. However, de Castro does not report confidence intervals, and as such ability to interpret his work is curtailed (Neale \& Miller, 1997).

\section{The Eating Inventory (Three Factor Eating Questionnaire) and Its Relation to Obesity Risk}

The Eating Inventory (EI; Stunkard \& Messick, 1985; 1988), also known as the Three-Factor Eating Questionnaire (TFEQ), is a self-report measure of eating behaviors that are believed to be particularly relevant to the development and maintenance of obesity. The EI has been widely used in obesity treatment (Stunkard \& Messick, 1988), and includes three subscales: Cognitive Restraint, Disinhibition, and Hunger. These subscales were developed using an exploratory factor analytic technique (Stunkard \& Messick, 1988). Previous research has found that obese individuals are more likely than controls to obtain high scores on each of these three subscales (Stunkard \& Messick, 1988; Yanovski, 2002). The extent to which these three subscales represent premorbid traits that contribute to obesity risk is unclear. Nonetheless, their strong association with obesity suggests that the traits measured by the EI might be candidate endophenotypes for obesity-related genetic studies. As such, exploring the extent to which genetic and environmental factors contribute to each of the traits measured by the EI is a worthy endeavor.

Given the magnitude and public health significance of the obesity epidemic (Brownell \& Wadden, 1992; Horgen $\&$ Brownell, 2002) and the challenges posed by its treatment (Brownell \& Wadden, 1992), instruments that can identify individual differences that may influence obesity risk are extremely useful. However, although the EI has been widely used for many years, limited evidence of its factorial validity exists. A recent study used confirmatory factor analysis and found that the EI did not conform to the threefactor model proposed by its developers (Mazzeo et al., 2003). Moreover, this study found that the factorial validity of the Restraint subscale was particularly problematic.

Thus, the purposes of this study were to examine further the structure of the EI, based on the covariance structure of the three subscales, and to investigate the relative influence of additive genetic and environmental factors on self-reported Cognitive Restraint, Disinhibition, and Hunger as measured by the EI in a population-based sample of female twins.

\section{Method \\ Participants}

Twins in this study derive from the population-based Virginia Twin Registry, which now constitutes part of the Mid-Atlantic Twin Registry (MATR). Female-female twin pairs, born between the years of 1934-1974, were eligible if both members had previously responded to a mailed questionnaire, the response rate to which was $-64 \%$. They have been approached for four waves of personal interviews from 1988 to 1997 . In late 1999 , we mailed questionnaires to all prior participants in these studies $(n=2163)$. Only modest resources were available for follow-up, which was largely limited to phone calls to non-responding twins whose cotwin had responded. We received a total of 1024 questionnaires, representing a $47 \%$ individual response rate. The present study focuses only on the 580 female twin individuals for whom complete data were available representing $342 \mathrm{MZ}$ twin and $230 \mathrm{DZ}$ twin individuals, of which $84 \mathrm{MZs}$ and $68 \mathrm{DZs}$ are upaired, yielding $129 \mathrm{MZ}$ pairs and $81 \mathrm{DZ}$ pairs.

Zygosity of twins was determined blindly by standard questions and photographs. For uncertain zygosity, blood was obtained for examination of DNA RFLP polymorphisms, using 8 highly informative probes, which, if all identical, produced a probability of monozygosity of 0.9997 (Spence et al., 1988). In addition, zygosity was recently revalidated by typing a selection of microsatellites through polymerase chain reactions (PCR) that showed an error rate of $4.5 \%$ (Wade et al., 2000).

\section{Representativeness of the Sample}

We attempted to predict participation in the female-female twin sample by major demographic variables. Participation was not significantly predicted by age, zygosity, or financial status. Only increasing education significantly predicted response $\left(\mathrm{OR}=1.23, \chi^{2}=16.62, d f=1, p<.0001\right)$, which is in keeping with known twin research bias. (Lykken et al., 1978).

\section{Measure}

Thirty-six items from Stunkard and Messick's (1985) EI were included in the eating disorders self-report questionnaire. These items were chosen for inclusion because they all have a similar response format. In contrast, the 15 excluded items have varying response options (e.g., responses to item 37 on the original EI range from "rarely" to "always," while responses to item 41 range from "easy" to "very difficult"). In the current study, item responses were recorded using a four-category response format (i.e., "always", "often", "sometimes", "never"). This response format differs from the true-false format used in prior studies of the EI. The expanded response format was used to improve measurement of the phenotype to gain more detailed information about participants' eating behaviors and attitudes, unavailable in mutually exclusive dichotomous responses. Participants were asked to mark the response that best described their eating attitudes and behaviors. In addition, modifications to the wording and ordering of some items 
have been documented in detail in a previous publication (Mazzeo et al., in press).

The EI is composed of three subscales: Cognitive Restraint, Disinhibition, and Hunger. The developers derived these factors using exploratory factor-analytic methods (Stunkard \& Messick, 1985; 1988). However, a recent confirmatory factor analysis (Mazzeo et al., in press), as well as several previous psychometric investigations (e.g., Ganley, 1988; Hyland et al., 1989; Karlsson set al., 2000) failed to replicate the three factor structure as put forth by Stunkard and Messick.

\section{Statistical Analysis}

Classical Twin Study Introduction

Data were analyzed using classical twin study methodology. This methodology is based on the knowledge that monozygotic (MZ) twins share all of their genetic code, whereas dizygotic (DZ) twins share variable amounts of DNA across the genome, but on average share half of their genetic code (Merriman, 1924; Siemens, 1924). Therefore, if a trait was determined entirely by fully penetrant genetic factors, one would expect the correlation between $\mathrm{MZ}$ twins to be one and the correlation of $\mathrm{DZ}$ twins to be roughly half of the MZ correlation.

Other than genetic influences, common environmental and individual environmental influences are acknowledged as possible contributors to twin covariance for a given trait. Common or shared environment effects are considered to be related to any sort of shared environment that is experienced by both members of the twin pair, such as socioeconomic status. Given that $\mathrm{MZ}$ and $\mathrm{DZ}$ twins are equally affected by shared environmental factors, the correlation between twin pairs of the shared environment is considered to be one for all twin pairs.

\section{ACE Modeling}

Structural equation modeling is a particularly useful tool for investigating $\mathrm{MZ}$ and $\mathrm{DZ}$ covariances for a given trait. These models are developed using the assumptions of classical twin methodology, and represent genetic and environmental influences on the $\mathrm{MZ}$ and $\mathrm{DZ}$ covariance. Given that the MZ and DZ correlations will differ, if genetic influences exist, we can construct a structural equation, and model the resulting difference in terms of genetic and common environmental influences. Specifically, in the classical twin study, we can quantify genetic influences (A), common environmental influences $(\mathrm{C})$, and specific or individual environmental (E) influences on a given trait. Because MZ twins fully share both common environment and genes, a rough estimate of individual environment is $1-r_{m z}$. Furthermore, the difference between MZ and DZ correlations should only be a reflection of the genetic contribution to the trait score, which allows us to determine the relative strength of $\mathrm{A}$ versus $\mathrm{C}$. The most common approach for determining the relative weights of $\mathrm{A}, \mathrm{C}$, and $\mathrm{E}$ is through structural equation modeling (SEM), utilizing a path analysis program such as Mx (Neale et al., 2002).

\section{Multivariate Models}

The ACE model is used for single traits, but in this case, we have multiple traits measured, namely the three subscales of the EI. We can fit multivariate models to these data to determine not only the univariate characteristics of the subscales, but also their interrelationships, and covariance structure.

The initial model used to determine the relation across multiple traits is the Cholesky Decomposition of the ACE model. In this model for three traits, we assume that nine latent factors exist, where the first A, C, and E factors affect all three subscales, the second $\mathrm{A}, \mathrm{C}$, and $\mathrm{E}$ affect two out of the three, and the third A, C, and E affect one of the prior two. This model reflects the combined covariance structure of the three traits, and provides an index of the nature of the covariance relationships among the three traits.

A second model applied in this study was the Common Pathway model. This model assumes that all three subscales are influenced by a single latent (unobserved) trait. The relative effect of this latent trait is indicated by the absolute value of the factor loadings onto the specific subscales. Furthermore, this latent trait is governed by an overriding ACE model, which reflects the relative proportions of variance due to $\mathrm{A}, \mathrm{C}$, and $\mathrm{E}$. In addition to the latent trait influences, specific A, C, and E estimates influence each subscale, to decompose their residual variances. In general, multivariate models (including both the Cholesky Decomposition and the Common Pathway) are more powerful than univariate models, primarily because they allow for covariance relationships to aid in optimization of the A, C, and E values. For a more extensive explication of ACE modeling and multivariate models, see Neale \& Cardon (1992).

\section{Results \\ Data Description}

Means and standard deviations for each of the three subscales are reported for $\mathrm{MZ}$ and $\mathrm{DZ}$ twins in Table $1 . \mathrm{MZ}$ and DZ correlations (and their corresponding 95\% confidence intervals) were calculated for each EI subscale to provide an initial examination of genetic and environmental effects (see Table 1).

In the current sample, MZ twins' correlation of Disinhibition was approximately twice as large as those of DZ

\section{Table 1}

Means, MZ, and DZ Twin Correlations of Eating Inventory Subscale Scores with 95\% Confidence Intervals

\begin{tabular}{lccr}
\hline Scale & Mean & $\mathrm{MZ}(95 \% \mathrm{Cl})(N=129)$ & $\mathrm{DZ}(95 \% \mathrm{Cl})(N=81)$ \\
\hline Disinhibition & 24.8 & $.45(.32-.57)$ & $.23(.16-.34)$ \\
Hunger & 19.2 & $.24(.11-.38)$ & $.20(.07-.34)$ \\
Restraint & 26.9 & $.31(.20-.42)$ & $.31(.17-.42)$ \\
\hline
\end{tabular}


twins, suggesting additive genetic effects. In contrast, there was little difference in either point estimates or confidence intervals between $\mathrm{MZ}$ and $\mathrm{DZ}$ twins for either Restraint or Hunger suggesting that these traits might be more strongly influenced by common environmental factors.

\section{Univariate Models}

A series of univariate twin analyses was performed using Mx (Neale et al., 2002). The statistics reported below are standardized according to the total variance of each of the subscales (See Table 2). Only Disinhibition manifested substantial additive genetic effects. In contrast, we observed smaller genetic effects and greater contributions of common environment to both Restraint and Hunger. Although the point estimates were higher for Restraint, the confidence intervals between the two traits were similar.

\section{Multivariate Models}

Cross trait covariances for $\mathrm{MZ}$ and $\mathrm{DZ}$ twins are presented in Table 3. The Cholesky Decomposition of the twin model was conducted, using all of the factors. Results indicated that the first genetic factor significantly influenced Disinhibition. Further, it suggested substantial covariance between Disinhibition and Hunger. The first common environmental factor was nonsignificant, and the first specific environmental factor significantly influenced Disinhibition, and again showed strong covariance with Hunger, and minimal covariance with Restraint.

The second set of factors examined the ACE model of Hunger and the covariance between Hunger and Restraint after the first factor captured the variance of Disinhibition. Both genetic and specific environmental factors significantly influenced Hunger. In addition, the covariance between Hunger and Restraint was nonsignificant, indicating no relationship between the two subscales not explained by Disinhibition. The second environmental factor was nonsignificant, and the specific environment factor only influenced Hunger, and did not significantly covary with Restraint. The final set of factors, which only influenced Restraint, demonstrated similar behavior to that of the univariate Restraint model, with significant common environment, and minimal genetic effects.

Next, we evaluated a Common Pathway model, which specifies that a latent trait affects all three subscales. This model also evaluates the influence of specific A, C, and E for each subscale. Results indicated that the latent trait had significant genetic and specific environmental influences, and nonsignificant common environmental influences. Further, the latent trait loaded significantly onto Disinhibition and Hunger, but not onto Restraint. In addition, the specific ACE effects on Disinhibition were nonsignificant, indicating that the latent factor is the only source of heritability. Hunger demonstrated only a significant specific environmental influence, but its overall variance appears to be due to the latent trait primarily. In contrast, with respect to the specific factors, both the common and specific environment demonstrated a significant effect on Restraint.

The difference in fit between the Cholesky Decomposition and the Common Pathway Model was 8.93 with 4 degrees of freedom. According to the Chisquare distribution of 4 degrees of freedom, the $p$-value associated with a value of 8.93 is approximately .063 . Thus, we cannot distinguish between the fit in the models according to statistical guidelines. Note that the independent pathway model was not tested, because in the three variable situation, it also is a saturated model, and thus provides no novel information.

\section{Discussion}

To the best of the authors' knowledge, this is the first population-based study of the genetic, common environmental

Table 2

Variance Components from Full Univariate ACE Twin Models (95\% Confidence Intervals) for Eating Inventory Subscales

\begin{tabular}{llccccc}
\hline Scale & $\mathrm{A}$ & $\mathrm{Cl}$ & $\mathrm{C}$ & $\mathrm{Cl}$ & $\mathrm{E}$ & $\mathrm{Cl}$ \\
\hline Disinhibition & .45 & $(.32-.57)$ & .00 & $(.00-23)$ & .55 & $(.43-.68)$ \\
Hunger & .08 & $(.00-.38)$ & .16 & $(.00-34)$ & .76 & $(.62-.89)$ \\
Restraint & .00 & $(.00-.30)$ & .31 & $(.04-.42)$ & .69 & $(.58-.80)$ \\
\hline
\end{tabular}

Table 3

Full Variance Covariance Matrix for MZ and DZ Females

\begin{tabular}{|c|c|c|c|c|c|c|c|c|c|c|c|c|}
\hline Scale & $\begin{array}{c}\text { Res1 } \\
\text { MZ }\end{array}$ & Dis1 & Hng1 & Res2 & Dis2 & Hng2 & $\begin{array}{c}\text { Res1 } \\
\text { DZ }\end{array}$ & Dis1 & Hng1 & Res2 & Dis2 & Hun2 \\
\hline Res1 & 46.79 & & & & & & 46.79 & & & & & \\
\hline Dis1 & 29.96 & 30.93 & & & & & 29.96 & 30.93 & & & & \\
\hline Hng1 & -2.08 & -2.81 & 25.82 & & & & -2.08 & -2.81 & 25.82 & & & \\
\hline Res2 & 21.35 & 11.50 & -2.62 & 46.79 & & & 11.54 & 6.85 & -2.66 & 46.79 & & \\
\hline Dis2 & 11.50 & 8.16 & -1.83 & 29.96 & 30.93 & & 6.85 & 5.87 & -1.76 & 29.96 & 30.93 & \\
\hline Hng2 & -2.62 & -1.83 & 8.12 & -2.08 & -2.81 & 25.83 & -2.66 & -1.76 & 8.02 & -2.08 & -2.81 & 25.82 \\
\hline
\end{tabular}




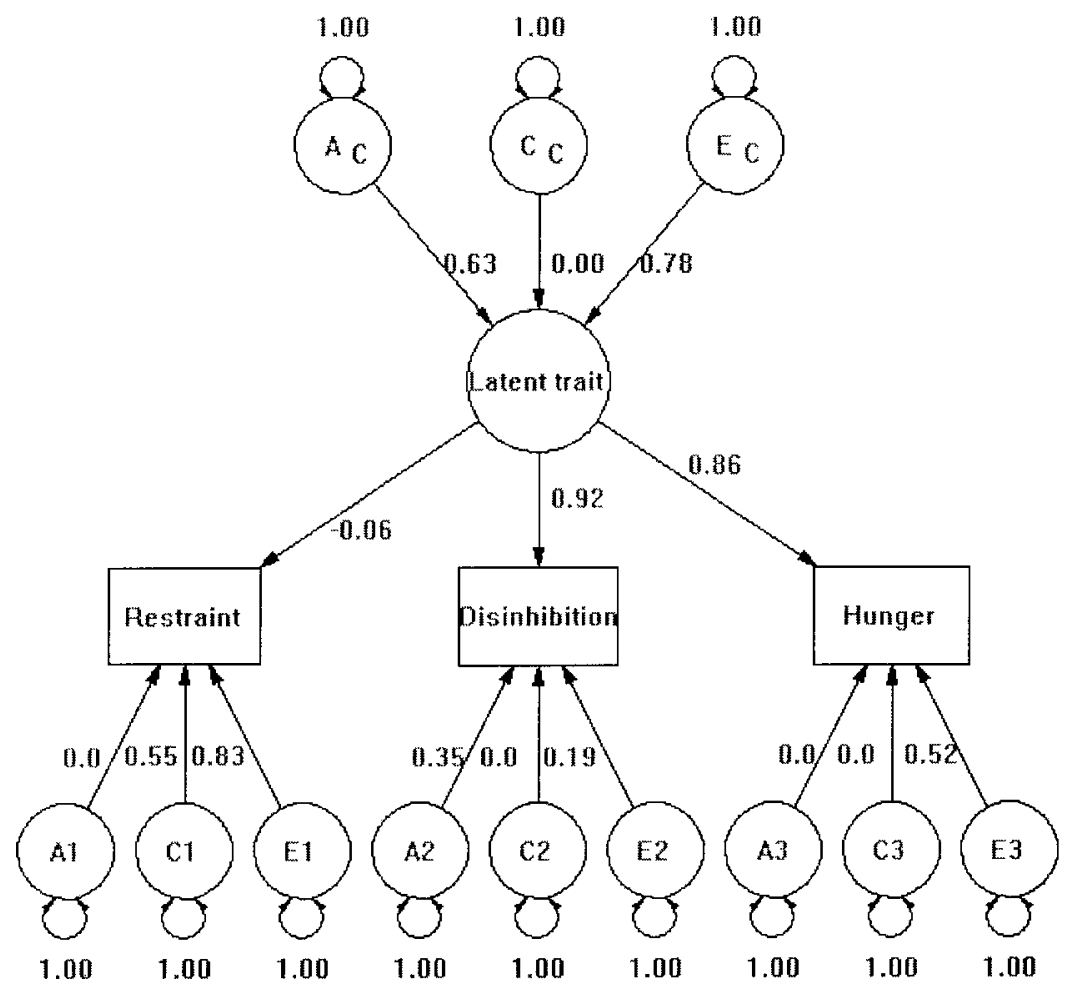

\section{Figure 1}

Common Pathway Model path diagram of eating inventory for females, with unsquared path coefficients.

\section{Table 4}

Standardized Cholesky Decomposition Latent Factor Loadings

\begin{tabular}{lcccccccccc}
\hline Scale & A1 & A2 & A3 & C1 & C2 & C3 & E1 & E2 & E3 & \\
\hline Disinhibition & .68 & & & 0 & & & .74 & & \\
Hunger & .45 & .19 & & .04 & .17 & & .65 & .55 & \\
Restraint & -.11 & -.2 & 0 & .43 & .03 & .28 & .03 & -.09 & .82 \\
\hline
\end{tabular}

and specific environmental influences on the EI. Results of both univariate and multivariate-level analyses indicated that Disinhibition is moderately heritable. In contrast, Restraint appears to be primarily influenced by common environmental factors. Furthermore, Disinhibition and Hunger appear to be partially overlapping constructs in terms of genetic and environmental contributions to their etiology, whereas Restraint appears to be empirically distinct.

Given the importance of identifying optimal behavioral endophenotypes for obesity, we shall interpret our results with reference to the utility of the various EI traits as such indices. These data clearly have implications for eating behaviors and obesity research. In particular, the behaviors and attitudes the EI measures are useful for furthering our understanding of the nature of weight regulation and liability to hunger, as they appear to measure eating behaviors that are differentially influenced by genetic and environmental factors. Moreover, one important characteristic of an appropriate endophenotype is heritability. A clear demonstration of heritability from twin studies supports the candidacy of endophenotypes for more biologically premised genetic research.

Along those lines, according to the present results, Restraint, as measured by the EI, does not appear to be an optimal endophenotype, given that the current study indicates that the behaviors and attitudes tapped by the Restraint subscale are most strongly influenced by shared events in the environment. This result is somewhat novel, in that the majority of eating disorder related traits have been shown to be primarily influenced by additive genetic effects (see Bulik, 2001 for a review), with one exception. Wade et al. (1998) noted that weight concerns as measured by the Eating Disorders Examination, unlike other EDE subscales, appeared to be influenced by common environment.

In contrast, the current results regarding Disinhibition point toward substantial additive genetic influence on the 
tendency to overeat, suggesting that this trait may be a promising endophenotype for obesity. This subscale was originally designed to measure "disinhibition of control" over eating in response to a variety of cues (e.g., social, contextual, emotional; Stunkard \& Messick, 1985, p. 76). However, more recent studies have found that it predicts overeating not only among individuals who typically exert high levels of control over their eating behaviors, but also among those whose eating is generally unrestrained (e.g., Westenhoefer et al., 1994). Indeed, high Disinhibition scores have been found to predict overeating in both correlational and experimental studies (e.g., Lowe \& Caputo, 1991; Westenhoefer et al., 1994). Moreover, Disinhibition scores are positively associated with BMI in both obese and normal-weight individuals (Foster et al., 1998; Williamson et al., 1995). Based on this previous research, and the current results, it appears that Disinhibition is worthy of further exploration as a behavioral endophenotype for weight dysregulation.

In addition to the information regarding genetic and environmental influences on the EI subscales, the current results provide insight into the measure's psychometric structure. In particular, the Common Pathway model suggests that Restraint is empirically distinct from both Disinhibition and Hunger. These results are consistent with those of previous studies that have found that Hunger and Disinhibition were strongly associated with one another, yet both were uncorrelated with Restraint (e.g., Collins et al., 1992; Williamson et al., 1995).

Further, it should be noted that several previous studies have found that the Restraint subscale is not unitary (e.g. Hyland et al., 1989; Ricciadelli \& Williams, 1997), which may have influenced its association with the other subscales in the current study. Specifically, Westenhoefer (1991) found that the Restraint subscale was composed of two factors: one reflecting flexible control (FC), and the other rigid control (RC) over eating. A subsequent study (Shearin et al., 1994) found that scores on FC were inversely related to BMI, while scores on RC were more strongly associated with disinhibited eating and bulimic behaviors. These psychometric issues are not unique to the Restraint subscale of the EI. Restraint has been identified as an important influence on eating behavior for decades (e.g., Herman \& Polivy, 1980; Ruderman, 1986), yet its measurement has remained challenging (e.g. Heatherton et al., 1986). These factorial validity issues further limit the usefulness of Restraint (as currently conceptualized and measured) in genetic studies of obesity.

In addition, the current multivariate-level results indicate that the covariance between Hunger and Disinhibition may be due to similar additive genetic factors. However, based on the combination of the univariate and multivariate-level results, Disinhibition appears to be the factor most strongly influenced by additive genetic effects, and thus, holds the most promise as a potential endophenotype.

Finally, although this study highlights some issues relevant to understanding the nature of the factors measured by the EI, the results should be interpreted with in the context of several methodological limitations. First, our study population was comprised entirely of Caucasian same-sex female twins. We cannot with confidence suggest that the observed results are generalizable to males or to individuals with different ethnic or racial backgrounds. Second, we altered the response format of the EI by expanding the number of response options. This approach, although valuable in that it provided more variance in response, may have influenced the function of the scale. Third, our response rate was not optimal in that only $47 \%$ of eligible like-sexed female twins responded. Although we were unable to identify parameters that influenced participation, it remains a possibility that unmeasured parameters that influence response may have biased the study sample.

\section{$\overline{\text { References }}$}

Bodurtha, J. N., Mosteller, M., Hewitt, J. K., Nance, W. E., Eaves, L. J., Moskowitz, W. B., et al. (1990). Genetic analysis of anthropomorphic measures in 11-year old twins: The Medical College of Virginia twin study. Pediatric Research, 28, 1-4.

Bouchard, C. (2002). Genetic influences on body weight. In C. G. Fairburn, \& K. D. Brownell (Eds.), Eating disorders and obesity: A comprehensive handbook (pp. 16-21). New York: Guilford.

Bouchard, C. Perusse, L., Rice, T., \& Rao, D. C. (1998). The genetics of human obesity. In G. A. Bray, C. Bouchard, \& W. P. T. James (Eds.), Handbook of obesity (pp. 157-190). New York: Marcel Dekker.

Bray, G. A., Bouchard, C., \& James, W. P. T. (1998). Definitions and proposed current classification of obesity. In G. A. Bray, C. Bouchard, \& W. P. T. James (Eds.), Handbook of obesity (pp. 31-40). New York: Marcel Dekker.

Brownell, K. D. (2002). The environment and obesity. In C. G. Fairburn, \& K. D. Brownell (Eds.), Eating disorders and obesity: A comprehensive handbook (pp. 433-438). New York: Guilford.

Brownell, K. D., \& Wadden, T. A. (1992). Etiology and treatment of obesity: Understanding a serious, prevalent, and refractory disorder. Journal of Consulting and Clinical Psychology, 60, 505-517.

Bulik, C. M., \& Allison, D. B. (2001). The genetic epidemiology of thinness. Obesity Reviews, 2, 107-115.

Bulik, C. M., \& Allison, D. B. (2002). Constitutional thinness and resistance to obesity. In C. G. Fairburn \& K. D. Brownell (Eds.), Eating disorders and obesity: A comprehensive handbook (pp. 22-25). New York: Guilford.

Bulik, C. M., Sullivan, P. F., Wade, T. D., \& Kendler, K. S. (2000). Twin studies of eating disorders: A review. International Journal of Eating Disorders, 27, 1-20.

Cardon, L. R. (1995). Genetic influences on body mass index in early childhood. In J. R. Turner, L. R. Cardon, \& J. K. Hewitt (Eds.), Behavioral genetic approaches in behavioral medicine (pp. 133-143). New York: Plenum.

Cohen, J. (1995). The earth is round $(p<.05)$. American Psychologist, 49, 997-1003.

Comuzzie A. G., \& Allison, D. B. (1998). The search for human obesity genes. Science, 280, 1374-1377.

de Castro, J. M. (1997). Inheritance of social influences on eating and drinking in humans. Nutrition Research, 17, 631-648. 
de Castro, J. M. (1999a). Inheritance of premeal stomach content influences on food intake in free living humans. Physiology and Behavior, 66, 223-232.

de Castro, J. M. (1999b). Heritability of hunger relationships with food intake in free-living humans. Physiology and Behavior, 67, 249-258.

French, S. A., Story, M., \& Jeffery, R. W. (2001). Environmental influences on eating and physical activity. Annual Review of Public Health, 22, 309-335.

Galton, F. (1865). Hereditary talent and character. MacMillan's Magazine, 12, 157-66, 318-27.

Ganley, R. M. (1988). Emotional eating and how it relates to dietary restraint, disinhibition, and perceived hunger. International Journal of Eating Disorders, 7, 635-647.

Hewitt, J. K. (1997). The genetics of obesity: What have genetic studies told us about the environment. Behavior Genetics, 27, 353-358.

Horgen, K. B., \& Brownell, K. D. (2002). Confronting the toxic environment: Environmental and public health actions in a world crisis. In T. A. Wadden, \& A. J. Stunkard (Eds.), Handbook of obesity treatment (pp. 95-106). New York: Guilford.

Hyland, M. E., Irvine, S. H., Thacker, C., Dann, P. L., \& Dennis, I. (1989). Psychometric analysis of the Stunkard-Messick Eating Questionnaire (SMEQ) and comparison with the Dutch Eating Behavior Questionnaire (DEBQ). Current Psychology: Research and Reviews, 8, 228-233.

Karlsson, J., Persson, L.O., Sjöström, L., \& Sullivan, M. (2000). Psychometric properties and factor structure of the ThreeFactor Eating Questionnaire (TFEQ) in obese men and women. Results from the Swedish Obese Subjects (SOS) study. International Journal of Obesity, 24, 1715-1725.

Keel, P. K., Heatheron, T. F., Harnden, J. L., \& Hornig, C. D. (1997). Mothers, fathers, and daughters: Dieting and disordered eating. Eating Disorders, 5, 216-228.

Kendler, K. S., Walters, E. E., Neale, M. C., Kessler, R., Heath, A, \& Eaves, L. (1995). The structure of genetic and environmental risk factors for six major psychiatric disorders in women. Archives of General Psychiatry, 52, 374-383.

Kendler, K., \& Prescott, C. (1999). A population-based twin study of lifetime major depression in men and women. Archives of General Psychiatry, 56, 39-44.

Klump, K. L., McGue, M., \& Iacono, W. G. (2000). Age differences in genetic and environmental influences on eating attitudes and behaviors in preadolescent and adolescent twins. Journal of Abnormal Psychology, 109, 239-251.

Klump, K. L., Wonderlich, S., Lehoux, P., Lilenfeld, L. R. R., \& Bulik, C. M. (2002). Does environment matter? A review of nonshared environment and eating disorders. International Journal of Eating Disorders, 31, 118-135.

Lowe, M. R., \& Caputo, G. C. (1991). Binge eating in obesity: Toward the specification of predictors. International Journal of Eating Disorders, 10, 49-55.

Lykken, D. T., Tellegen, A., \& De Rubeis, R. (1978). Volunteer bias in twin research; The rule of two thirds. Social Biology, 25, 1-9.

Maes, H., Neale, M., \& Eaves, L. (1997). Genetic and environmental factors in body mass index. Behavior Genetics, 27, $325-351$.
Manson, J. E., Skerrett, P. J., \& Willett, W. C. (2002). Epidemiology of health risks associated with obesity. In C. G. Fairburn, \& K. D. Brownell (Eds.), Eating disorders and obesity: A comprehensive handbook (pp. 422-428). New York: Guilford.

Mazzeo, S. E., Aggen, S. H., Anderson, C., Tozzi, F., \& Bulik, C. M. (2003). Investigating the structure of the eating inventory (TFEQ): A confirmatory approach. International Journal of Eating Disorders, 34, 255-264.

Merriman, C. (1924). The intellectual resemblence of twins. Psychology Monograph, 33, 1-58.

Mokdad, A. H., Serdula, M. K., Dietz, W. H., Bowman, B. A., Marks, J. S., \& Koplan, J. P. (1999). The spread of the obesity epidemic in the United States, 1991-1998. JAMA, 282(16), 1519-1522.

Mokdad, A. H., Bowman, B. A., Ford, E. S., Vinicor, F., Marks, J. S., \& Koplan, J. P. (2001). The continuing epidemics of obesity and diabetes in the United States. JAMA, 286(10), 1195-1200.

Must, A., Spadano, J., Coakley, E. H., Field, A. E., Colditz, G., \& Dietz, W. H. (1999). The disease burden associated with overweight and obesity. Journal of the American Medical Association, 282, 1523-1529.

Neale, M. C., \& Cardon, L. R. (1992). Methodology for genetic studies of twins and families. Dordrecht: Kluwer Academic Publishers.

Neale, M. C., \& Miller, M. B. (1997). The use of likelihoodbased confidence intervals in genetic models. Behavior Genetics, 27, 113-120.

Neale, M. C., Boker, S. M., Xie, G., \& Maes, H. H. (2002). Mx: Statistical modeling. Richmond: VCU Department of Psychiatry.

Pike, K. M., \& Rodin, J. (1991). Mothers, daughters, and disordered eating. Journal of Abnormal Psychology, 100, 198-204.

Pi-Sunyer, F. X. (2002). Medical complications of obesity in adults. In C. G. Fairburn, \& K. D. Brownell (Eds.), Eating disorders and obesity: A comprehensive handbook (pp. 467-472). New York: Guilford.

Plomin, R., DeFries, J. C., \& McClearn, G. E. (1990). Behavioral genetics: A primer. New York: Freeman.

Siemens, H. (1924). Die Zwillingspathologie. Berlin: SpringerVerlag.

Spence, J., Corey, L., Nance, W., Marazita, M., Kendler, K. S., \& Schieken, R. (1988). Molecular analysis of twin zygosity using VNTR DNA probes. American Journal of Human Genetics, 43, A159.

Stunkard, A. J., Harris, J. R., Pedersen, N. L., \& McClearn, G. E. (1990). The body mass index of twins who have been reared apart. New England Journal of Medicine, 322, 1483-1487.

Stunkard, A. J., \& Messick, S. (1985). The Three-Factor Eating Questionnaire to measure dietary restraint and hunger. Journal of Psychosomatic Research, 29, 71-83.

Stunkard, A. J., \& Messick, S. (1988). Eating Inventory manual. San Antonio: The Psychological Corporation.

Wade, T. D., Martin N., \& Tiggemann, M. (1998). Genetic and environmental risk factors for the weight and shape concerns characteristic of bulimia nervosa. Psychological Medicine, 28, 761-771. 
Wade, T. D., Bulik, C. M., Neale, M., \& Kendler, K. S. (2000). Anorexia nervosa and major depression: Shared genetic and environmental risk factors. American Journal of Psychiatry, 157, 469-471.
Westenhoefer, J., Broeckmann, P., Münch, A. K., \& Pudel, V. (1994). Cognitive control of eating behaviour and the disinhibition effect. Appetite, 23, 27-41. 